\title{
Panuveíte em Artrite Indiferenciada HLA-B27 Positiva
}

\section{Panuveitis in HLA-B27 Positive Undifferentiated Arthritis}

\author{
Mário Sérgio Ferreira Santos ${ }^{(1)}$, Vitor Cortizo ${ }^{(2)}$, Cícero Ricardo Torres da Costa ${ }^{(3)}$, \\ Ronnielly Melo Tavares ${ }^{(3)}$, Ricardo Eric Barros Lopes ${ }^{(3)}$
}

\section{RESUMO}

Entre os vários tipos de inflamação ocular associados às doenças reumatológicas, a uveíte anterior é particularmente comum nas espondiloartropatias, em especial quando associada à presença do genótipo HLA-B27. Relatou-se o caso de um paciente com artrite indiferenciada HLA-B27 positivo, complicado com panuveíte e vasculite da retina, refratária ao tratamento imunossupressor tradicional, que obteve boa resposta clínica ao uso de anti-TNF-alfa.

Palavras-chave: HLA-B27, artrite indiferenciada, panuveíte, uveíte.

\section{INTRODUÇÃO}

Uveíte é uma desordem inflamatória ocular que, eventualmente, se instala em doenças reumatológicas, com predileção pelas espondiloartropatias, em especial a espondilite anquilosante (EA) e a artrite reativa. As crises são geralmente unilaterais, autolimitadas e recorrentes ${ }^{(1)}$.

A manifestação ocular mais freqüentemente encontrada nos pacientes com artrite HLA-B27 positiva é a uveíte anterior aguda $(\mathrm{UAA})^{(2)}$. O paciente apresentado nesse relato de caso evoluiu com panuveíte e vasculite da retina, suscitando ampla investigação para doenças sistêmicas.

\section{RELATO DE CASO}

Homem, 24 anos, branco, solteiro, procurou atendimento médico por estar apresentando artralgia de joelhos há três semanas e dor e vermelhidão ocular à direita na última semana. Referia dois episódios de faringoamigdalite precedendo os sintomas, o último, duas semanas antes do início da artralgia. Negava sintomas urinários ou gastrintestinais, bem como história familiar de EA, psoríase ou doença inflamatória intestinal. No exame físico, observou-se

\begin{abstract}
Among the several types of ocular inflammation associated to the rheumatic diseases, anterior uveitis is particularly common in the spondyloarthropathies, especially when associated to the presence of the HLA-B27 genotype. We report the case of HLAB27 positive patient with undifferentiated arthritis, complicated with panuveitis and retinal vasculitis, that was refractory to the traditional imunossupressive treatment, and had a good clinical response with anti-TNF-alpha therapy.
\end{abstract}

Keywords: HLA-B27, undifferentiated arthritis, panuveitis, uveitis.

derrame articular bilateral de joelhos mais acentuado à esquerda. Não havia sinais de entesite ou sacroiliíte, não apresentava úlceras orais, genitais, nem lesões cutâneas. $\mathrm{O}$ exame oftalmológico revelou UAA à direita. Exames laboratoriais iniciais: hemoglobina $(\mathrm{Hb})=11,5 \mathrm{~g} / \mathrm{dL}$, leucócitos $=16.300 \mathrm{~mm}^{3}$, plaquetas $=230.000 \mathrm{~mm}^{3}$, velocidade de hemossedimentação (VHS) $30 \mathrm{~mm}$ na primeira hora, proteína $\mathrm{C}$ reativa $(\mathrm{PCR}) 2,1 \mathrm{mg} / \mathrm{dL}$ (referência $<0,8 \mathrm{mg} / \mathrm{dL}$ ), fator reumatóide $(\mathrm{FR})$ e fator antinuclear $($ FAN) foram negativos, antiestreptolisina $\mathrm{O}(\mathrm{ASLO})<200$ em duas ocasiões, radiografia da bacia nas incidência AP e Ferguson não mostraram sinais de sacroiliíte. Foi prescrito antiinflamatório não-hormonal, além de corticosteróide na forma de colírio. Teve boa resposta ao tratamento inicial, mas depois de uma semana livre de medicação voltou a apresentar artrite e uveíte, dessa vez do lado contralateral. O líquido sinovial, obtido por artrocentese do joelho esquerdo, revelou-se inflamatório, mas negativo para cristais e bactérias.

Dois meses depois da primeira consulta, em novembro de 2006, sem uso de medicação, o paciente apresentou piora do quadro ocular à direita, com déficit visual importante. Nova

Recebido em 23/3/2008. Aprovado, após revisão, em 18/9/2008. Declaramos a inexistência de conflitos de interesse

1. Pós-graduando da disciplina de Reumatologia da Faculdade de Medicina da Universidade de São Paulo (FMUSP) e reumatologista em Teresina, PI.

2. Doutor em Ciências pela FMUSP e oftalmologista em Teresina, PI.

3. Graduandos de Medicina da Faculdade de Ciências Médicas da Universidade Estadual do Piauí (Facime- Uespi).

Endereço para correspondência: Mário Sérgio Ferreira Santos, Av. Kennedy, 4560, casa 13, Terra dos Pássaros, 64062-100, Teresina, PI, e-mail: m.cla@uol.com.br 
avaliação laboratorial mostrou atividade da enzima conversora da angiotensina (ECA), testes de PPD, sorologia para sífilis, HIV, vírus B e vírus $\mathrm{C}$, toxoplasmose, citomegalovírus, clamídia, Epstein-Barr e radiografia do tórax foram normais ou negativos; porém o HLA-B27 foi positivo. Introduziuse metotrexato (MTX), $10 \mathrm{mg} / \mathrm{semana}$. O quadro ocular agravou-se e nova avaliação oftalmológica detectou panuveíte com vasculite da retina e papilite óptica à direita. Recebeu prednisona, na dose de $80 \mathrm{mg} /$ dia, por via oral. Apresentou boa resposta clínica, a dor e a hiperemia ocular desapareceram, recuperando parcialmente a visão do olho direito. Pela possibilidade de doença de Behçet, foi iniciado ciclosporina $250 \mathrm{mg} /$ dia, sendo aumentado mais tarde para $450 \mathrm{mg} / \mathrm{dia}$ e reduzindo-se gradativamente a prednisona.

Em março de 2007, três meses após o início da ciclosporina, permanecia déficit visual importante do olho direito e a avaliação oftalmológica revelou panuveíte associada à papilite bilateral (Figuras 1 e 2). Por causa da refratariedade do caso, iniciou-se infliximabe, na dose de $3 \mathrm{mg} / \mathrm{kg}$. A melhora clínica foi notada após a terceira infusão, sendo possível a diminuição da prednisona para $5 \mathrm{mg} /$ dia. $\mathrm{Na}$ evolução, apresentou recidiva do quadro ocular, que foi controlado com aumento da dose do infliximabe para $5 \mathrm{mg} / \mathrm{kg}$, em intervalos mais curtos (cada quatro semanas) associado a MTX $15 \mathrm{mg} /$ semana.

Atualmente, encontra-se assintomático, em uso de $3 \mathrm{mg}$ de prednisona ao dia, MTX e infliximabe, já tendo feito oito infusões doses deste último. Apresenta visão completa à esquerda, com regressão total da papilite e panuveíte, persistindo edema macular residual à direita com redução na acuidade visual (Figuras 3 e 4 ).

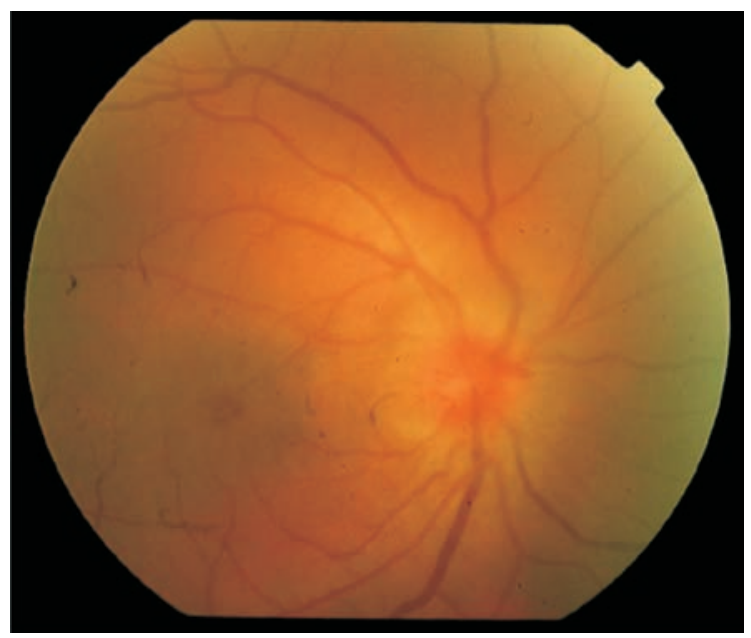

Figura 1 - Edema de papila e mácula em olho direito, pré-tratamento.

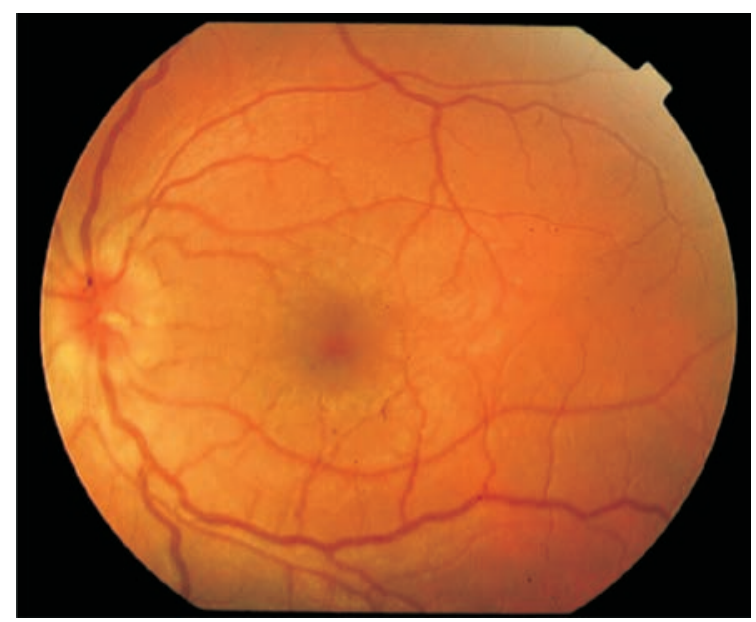

Figura 2 - Edema de papila em olho esquerdo, pré-tratamento.

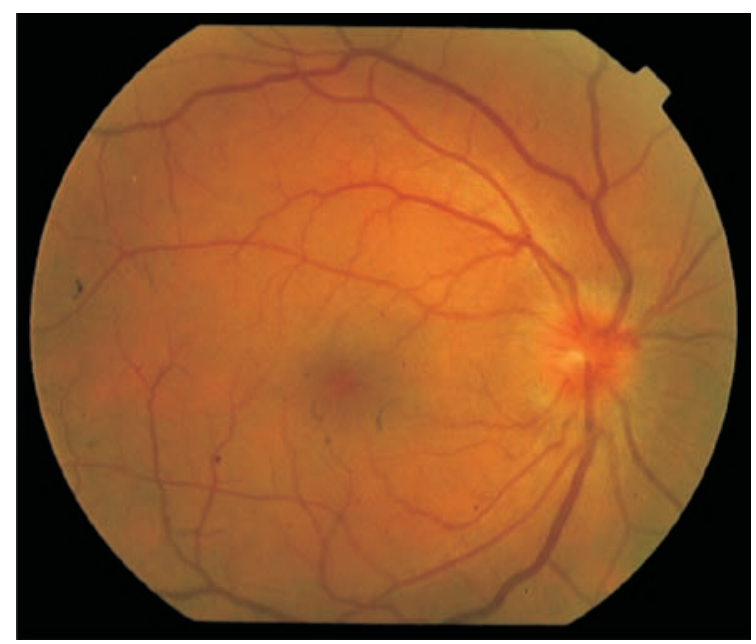

Figura 3 - Melhora do edema de papila e mácula em olho direito, pós-tratamento.

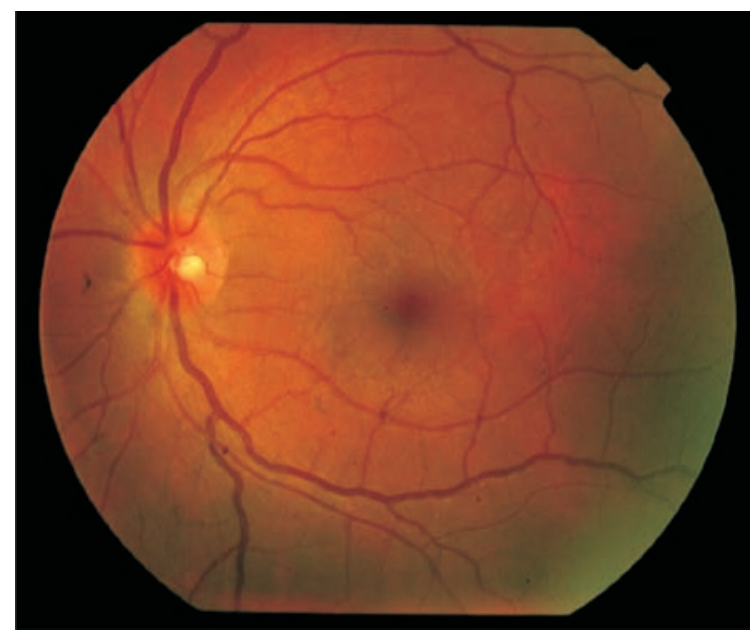

Figura 4 - Resolução completa do edema de papila em olho esquerdo, póstratamento. 


\section{DISCUSSÃO}

O achado de uveíte em um homem jovem associado à oligoartrite de grandes articulações de membros inferiores levanta fortemente a possibilidade de espondiloartropatia. No entanto, a evolução atípica com envolvimento ocular grave (panuveíte) faz necessária a investigação criteriosa de diagnósticos diferenciais, como doença de Behçet, sarcoidose, sífilis e tuberculose.

Sarcoidose e sífilis são causas potenciais das mais diferentes formas de doença inflamatória ocular (DIO). Dessa forma, os exames FTA-ABS e a radiografia do tórax são de grande valia na investigação das uveítes ${ }^{(3)}$. A forma aguda da sarcoidose, conhecida como síndrome de Löfgren, é constituída por artrite, eritema nodoso e linfoadenopatia hilar bilateral. O eritema nodoso predomina no sexo feminino. Já o envolvimento articular é mais encontrado no sexo masculino, em geral na forma de artrite ou inflamação periarticular de tornozelo ${ }^{(4)}$. O teste treponêmico negativo com radiografia do tórax e níveis de ECA normais contribuíram para excluir essas duas possibilidades.

As apresentações mais comuns da tuberculose ocular são uveíte anterior crônica, coroidite e escleroceratite ${ }^{(5)}$. A maioria dos pacientes não tem história de enfermidade pulmonar ou sistêmica. Em até metade dos casos a radiografia do tórax é normal( ${ }^{(6)}$. $\mathrm{O}$ achado de um $\mathrm{PPD}$ não-reator em indivíduos imunocompetentes deixa menos provável infecção tuberculosa ativa.

Embora reconhecida como causa de panuveíte, com vasculite da retina, a manifestação ocular mais comum na doença de Behçet é a iridociclite aguda, grave e recorrente $^{(1)}$. A ausência de úlceras orais e/ou genitais fala contra o diagnóstico de doença de Behçet. As grandes séries de casos da doença registram $100 \%$ de envolvimento mucocutâneo e reforçam a origem mediterrânea e da rota da seda como importantes elementos epidemiológicos ${ }^{(7)}$. Formas incompletas dessa enfermidade têm sido descritas, a exemplo de outras doenças reumáticas (lúpus sem manifestações extra-renais, dermatomiosite sine miosite), pacientes nos quais faltem achados mucocutâneos, mas não outras manifestações, como aneurismas arteriais, trombose venosa e teste de patergia positivo ${ }^{(8)}$.

Além da topografia anterior, da instalação aguda e do curso clínico autolimitado, as uveítes das espondiloartro- patias costumam ser recorrentes e dificilmente cronificam. Sinequias aparecem freqüentemente, sendo raro o envolvimento posterior (úvea posterior) e muito raro as ceratopatias em banda e precipitados ceratíticos granulomatosos ${ }^{(2)}$. Em uma avaliação retrospectiva de 350 pacientes com espondiloartropatia, uveíte posterior só foi encontrada em duas pacientes, atribuída à presença de tuberculose $\mathrm{e}$ toxoplasmose, respectivamente ${ }^{(9)}$.

A presença do genótipo HLA-B27, em indivíduos com uveíte, guarda forte correlação com a presença atual ou futura de espondiloartropatia. A EA e a artrite reativa foram encontradas em $84 \%$ de indivíduos com UAA e genotipagem HLA-B27 positiva ${ }^{(2)}$. Na ausência de episódio infeccioso prévio, seja geniturinário ou gastrintestinal, torna-se pouco provável a artrite reativa. Dessa forma, excluindo-se os principais diagnósticos diferenciais, o mais provável era espondiloartropatia. Porém como não preenchia critérios para um subgrupo específico, utilizou-se a denominação mais adequada, qual seja, artrite indiferenciada HLA-B27 positiva.

Para o tratamento da panuveíte com envolvimento da retina, optou-se, inicialmente, por imunossupressores tradicionais. MTX e ciclosporina mostraram-se ineficazes. Decidiu-se então pelo uso do anti-TNF- $\alpha$ (infliximabe). O fator de necrose tumoral alfa (TNF- $\alpha$ ) é o mediador inflamatório em modelos animais de uveíte ${ }^{(10,11)}$. Essa citocina tem sido encontrada em altos níveis no soro e no humor aquoso de pacientes com uveíte ${ }^{(12)}$. Existe, portanto, base racional para uso do agente biológico anti-TNF- $\alpha$ nessa condição clínica.

A eficácia clínica dos imunobiológicos tem sido comprovada em diferentes estudos. Seu uso na DIO, com ou sem artrite é bastante promissor. Um estudo retrospectivo de 27 pacientes com DIO, refratária à terapia imunossupressora tradicional, demonstrou o benefício dessa estratégia terapêutica ${ }^{(13)}$. Os pacientes receberam $5 \mathrm{mg} / \mathrm{kg} /$ dose em intervalos de duas a oito semanas. Esse estudo apresenta limitações, por ser retrospectivo, por faltar grupo-controle, além do pequeno número de pacientes.

Dessa forma, a genotipagem HLA-B27 associada à exclusão de outras doenças sistêmicas foram fundamentais para a elucidação diagnóstica e o tratamento. A exclusão de doenças infecciosas foi essencial para a indicação e o uso seguro e bem-sucedido do anti-TNF- $\alpha$. 


\section{REFERÊNCIAS}

1. O'Day DM, Horn JD: The eye and rheumatic disease. In: Ruddy S, Harris ED, editores. Kelley's Textbook of Rheumatology. $7^{\text {a }}$ ed. Philadelphia: Saunders; cap. 44, 2000.

2. Rosenbaum JT: Characterization of uveitis associated with spondyloarthritis. J Rheumatol 16: 792-6, 1989.

3. Banares A, Jover JA, Fernandez-Gutierrez B, et al.: Patterns of uveitis as a guide in making rheumatologic and immunologic diagnoses. Arthritis Rheum 40(2): 358-70, 1997.

4. Idali F, Wikén M, Wahlström J, et al.: Reduced Thl response in the lungs of HLA-DRBI*0301 patients with pulmonary sarcoidosis. Eur Respir J 27: 451-9, 2006.

5. Demirchi H, Shields J A, Eagle Jr RC: Ocular tuberculosis masquerading as ocular tumors. Surv Ophtalmol 49: 78-89, 2004.

6. Levecq LJ, De Potter P: Solitary choroidal tuberculoma in an immunocompetent patient. Arch Ophtalmol 123: 864-6, 2005.

7. Tugol-Tutkun I, Onal S, Alton-Yoycioglu R, Huseyin-Altunbas $\mathrm{H}$, Urgancioglu M: Uveitis in Behçet disease: an analysis of 880 patients. Am J Ophthalmol 138(3): 373-80, 2004.
8. Pandrea A, Rudinskaya A, Klein B, Krebs T: What does it take do diagnose Behçet disease? J Clin Rheumatol 13: 31-4, 2007.

9. Sampaio-Barros PD, Conde RA, Bonfiglioli R, Bértolo MB, Samara AM: Characterization and outcome of uveitis in 350 patients with spondyloarthropathies. Rheumatol Int 26(12): 1143-6, 2006.

10. Mo J-S, Matsukawa A, Ohkawara S, Yoshinaga M: Involvement of TNF[alpha], IL-1 [beta], and IL-1 receptor antagonist in LPSinduced rabbit uveitis. Exp Eye Res 66(5): 547-57, 1998.

11. Koizumi K, Poulaki V, Doehman S, et al.: Contribution of TNF[alpha] to leukocyte adhesion, vascular leakage, and apoptotic cell death in endotoxin-induced uveitis in vivo. Invest Ophthalmol Vis Sci 44(5): 2184-91, 2003.

12. Pérez-Guijo V, Santos-Lacomba M, Sanchez-Hernandez M, et al.: Tumour necrosis factor-alpha levels in aqueous humor and serum from patients with uveitis: the involvement of HLA- B27. Curr Med Res Opin 20(2): 155-7, 2004.

13. Sobrin L, Kim EC, Christen W, Papadaki T, Letko E, Foster CS: Infliximab therapy for the treatment of refractory ocular inflammatory disease. Arch Ophthalmol 125(7): 895-900, 2007. 